\title{
АНАЛИЗ РЫНКА ИПОТЕЧНОГО КРЕДИТОВАНИЯ И ПЕРСПЕКТИВЫ ЕГО РАЗВИТИЯ
}

\section{ANALYSIS OF THE MORTGAGE LENDING MARKET AND PROSPECTS FOR ITS DEVELOPMENT}

\author{
A. Savderova \\ E. Antonovskaya \\ K. Troitskaya
}

Summary: The article presents an analysis of the current state of the mortgage lending market by key parameters. An overview of the regulatory body's measures aimed at supporting this segment of the banking market is presented. The prospects of its development in the conditions of the current macroeconomic situation are highlighted.

Keywords: mortgage lending, mortgage portfolio, interest rate, overdue debt, real estate market, real estate, banking sector.
Савдерова Алина Федоровна

К.э.Н., доцент, ФГБОУ ВО «Чувашский государственный университет им. И.Н. Ульянова» (2. Чебоксары)

savderova@mail.ru

Антоновская Елена Анатольевна

К.э.Н., доцент, ФГБОУ ВО «Чувашский государственный университет им. И.Н. Ульянова», (2. Чебоксары) buyanova-e@bk.ru

троицкая Ксения Владимировна ФГБОУ ВО «Чувашский государственный университет им. И.Н. Ульянова», (2. Чебоксары) ksyu.troitskaya@mail.ru

Аннотация: В статье представлен анализ текущего состояния рынка ипотечного кредитования по ключевым параметрам. Представлен обзор мер регулирующего органа, направленных на поддержку данного сегмента банковского рынка. Выделены перспективы его развития в условиях сложившейся макроэкономической ситуации.

Ключевые слова: ипотечное кредитование, ипотечный портфель, процентная ставка, просроченная задолженность, рынок недвижимости, недвижимое имущество, банковский сектор.

задачей коммерческих банков является формирование грамотной кредитной политики и разработка новых подходов к ипотечному кредитованию, которые будут способствовать привлечению новых клиентов, что поможет выйти на лидирующие позиции в данной сфере рынка банковских продуктов и услуг.

Начиная с 2012 года в банковском секторе наблюдается рост объема предоставленных ипотечных кредитов с 1 трлн. рублей до 3,5 трлн. рублей в 2014 году. Однако по итогам 2015 года объем выданных ипотечных кредитов сократился на 33\%, что связано с установлением в начале 2015 года максимальной за рассматриваемый период средневзвешенной процентной ставки на уровне $14,7 \%$ в связи с ухудшением макроэкономической ситуации. С 2016 года возобновился рост ипотечного кредитования в России, в том числе за счет внедрения государственной программы субсидирования процентных ставок по ипотечным кредитам на покупку жилья на рынке первичной недвижимости. Однако впервые за четыре года объем выданных ипотечных кредитов банковского сектора сократился, и за 2019 год рынку ипотечного кредитования не удалось достигнуть рекордно высоких значений 2018 года. По данным Центрального банка Российской Федерации в 2019 году общее количество выданных ипотечных кредитов составило около 1,3 млн. на сумму 2,8 трлн. рублей, что по сравнению с 2018 
годом ниже в количественном выражении на 14\% и в денежном выражении на 5\% [2]. Это связано в основном с более высоким уровнем процентных ставок по ипотечным кредитам на протяжении первой половины 2019 года, ростом цен на недвижимое имущество, а также с сокращением объемов выдачи ссуд с небольшим первоначальным взносом.

В результате снижения с 2015 года процентных ставок по ипотечным кредитам наблюдается рост доли ипотечных кредитов в общем объеме кредитного портфеля банковского сектора. С начала 2015 года удельный вес количества заемщиков по ипотеке вырос на 7,5 п.п. и составил $19,5 \%$ от общего количества заемщиков, а доля суммарного ипотечного кредитного портфеля увеличилась на 11 п.п. и составила 48,9\%.

По данным Центрального банка Российской Федерации ипотечный портфель имеет очень хорошее качество, поскольку по состоянию на начало 2020 г. доля кредитов с просрочкой платежей более 90 дней приходится менее 1,4\%. При этом доля валютных ипотечных жилищных кредитов составляет менее 0,5\%, что также говорит о невысоких рисках данного сегмента [2].

Вследствие уменьшения объемов ипотечного кредитования произошло замедление темпа прироста ипотечного портфеля в 2019 году по сравнению с 2018 годом с 24 до 17\%, а размер совокупной задолженности по ипотечным кредитам по состоянию на 01.01.2020 составил 7,5 трлн. рублей. Ипотечное кредитование, традиционно лидирующее по темпам прироста, в 2019 году уступило другим сегментам розничного кредитования, активному росту которых способствовала реализация отложенного спроса населения в отношении необеспеченного потребительского кредитования и автокредитов на фоне установления банками минимальных процентных ставок за все время развития российского рынка, а также проявление повышенного интереса банков к розничному кредитованию по причине сжатия иных доходных сегментов, например, корпоративного кредитования.

В течение 2012-2019 гг. среднерыночная ставка по ипотеке значительно колебалась в интервале от 9 до $14,7 \%$. Максимальная процентная ставка ипотечного кредитования наблюдается по состоянию на 01.04.15 в размере $14,7 \%$, что связано с рекордным повышением ключевой ставки Банка России. В результате повторного увеличения ключевой ставки в декабре 2018 года в начале 2019 года выросла стоимость ипотечных кредитов. В течение 2019 года значение средневзвешенных ставок наблюдалось на более высоком уровне по сравнению с 2018 годом, и это несмотря на то, что происходило активное снижение ставок с лета 2019 года, и по его итогам было достигнуто минимальное значение в $9 \%$ за весь рассматриваемый период с 2012 по 2019 год. Это послужило одной из причин замедления рынка ипотечного кредитования. По прогнозам рейтингового агентства «Эксперт РА» на фоне увеличения доходности облигаций федерального займа (ОФЗ) и стоимости фондирования для банков по причине волатильности на финансовых рынках ожидается рост ставок по ипотечным кредитам в 2020 году, процентная ставка по ипотеке с высокой вероятностью должна превысить 10\% уже в первой половине 2020 года [36].

Однако по данным Центрального банка Российской Федерации средневзвешенные ставки по ипотечному жилищному кредитованию в первые четыре месяца 2020 года достигли рекордно низких значений на уровне ниже 9\%. По состоянию на 01.05.2020 средневзвешенная ставка составила 8,32\%, что ниже по сравнению со ставкой на 01.01.2020 на 0,68 п.п. [2].

Также причиной снижения спроса на ипотечные кредиты является рост цен на недвижимость. На протяжении 2019 года стоимость увеличивалась, как на первичное, так и вторичное жилье. Однако рост цен на первичное жилье по причине изменения механизма финансирования застройщиков происходил опережающими темпами по сравнению с ростом цен вторичного жилья, вследствие чего увеличился разрыв в ценах на жилье данных двух категорий (рис. 1).

В среднесрочной перспективе данная динамика сохранится, поскольку в 2019 году застройщики перешли на банковское фондирование и работу по эскроу-счетам, и это отразится на постепенном увеличении затрат на строительство по мере завершения проектов, которые на данный момент достраиваются по прежним правилам. Также на увеличение цен на первичное жилье повлияет рост затрат застройщиков по причине закупки импортных материалов и техники вследствие скачка курсов в 2020 году. Кроме того в результате высокой волатильности на финансовых рынках в начале 2020 года возможно усиление инвестиционного спроса на недвижимое имущество в качестве средства сохранения сбережений, что поддержит стоимость на жилье.

Увеличение цен на жилье на фоне снижения реальных доходов населения привело в 2019 году к росту среднего размера ипотечного кредита на $10 \%$, а именно с 2,0 до 2,2 млн. рублей. Тем не менее, наибольшую популярность среди заемщиков также имеют ипотечные кредиты суммой до 3 млн. рублей, на долю которых в 2019 году пришлось 57\% всего объема выданных ипотечных ссуд, что существенно меньше по сравнению с 2018 годом на 7 п.п. (рис. 2). Стоит отметить, что в 2019 году зна- 


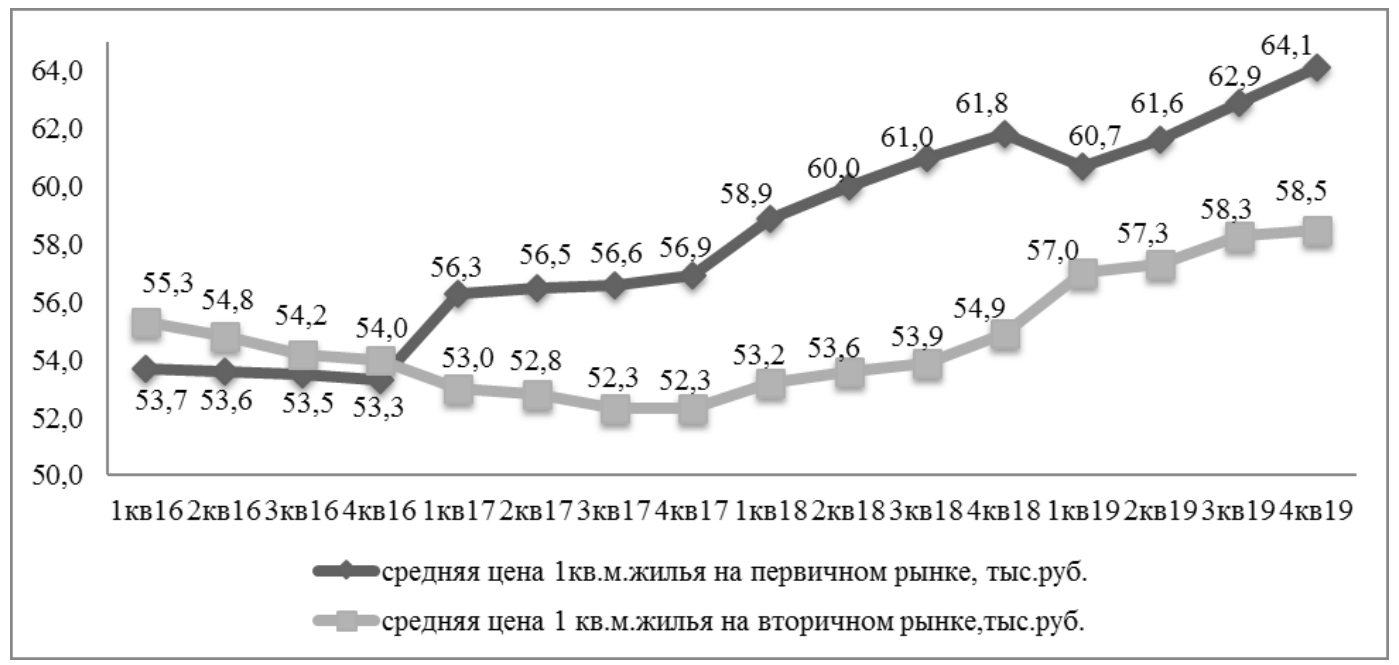

Рис. 1. Динамика стоимости 1 кв. м. первичного и вторичного жилья за 2016-2019 гг.

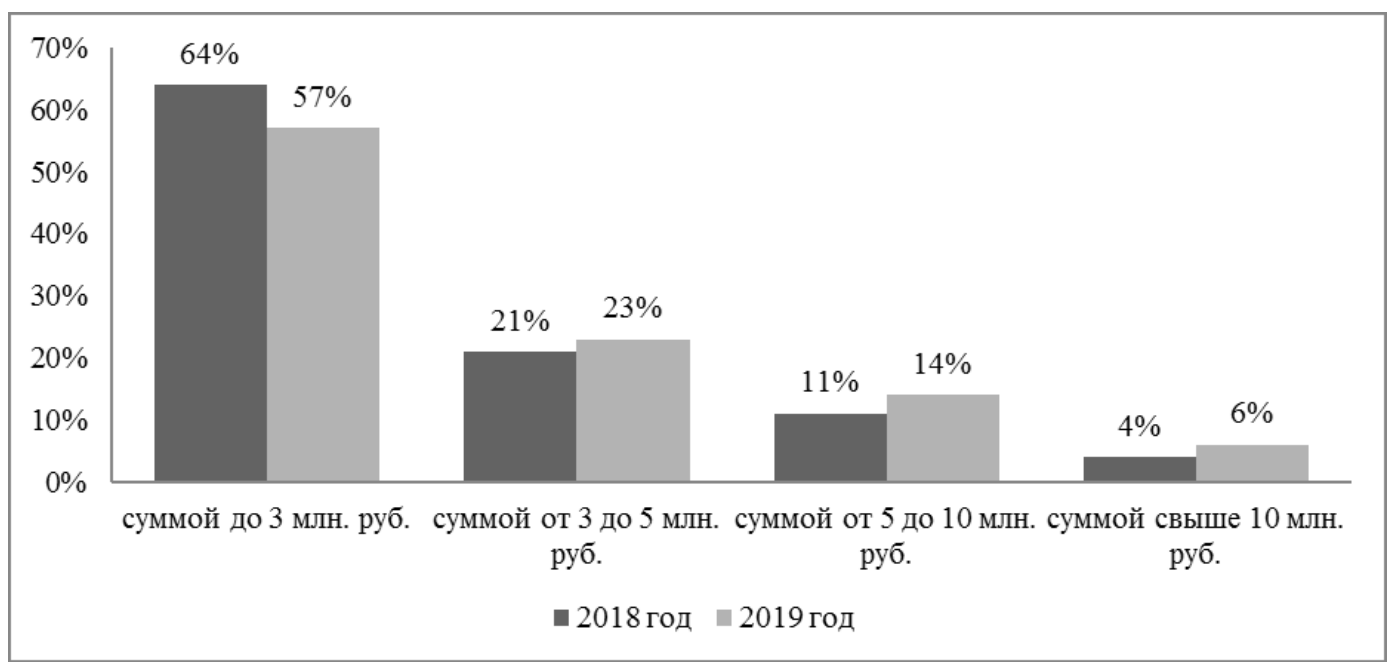

Рис. 2. Структура ипотечного кредитного портфеля банковского сектора по размеру ссуды в 2018-2019 гг.

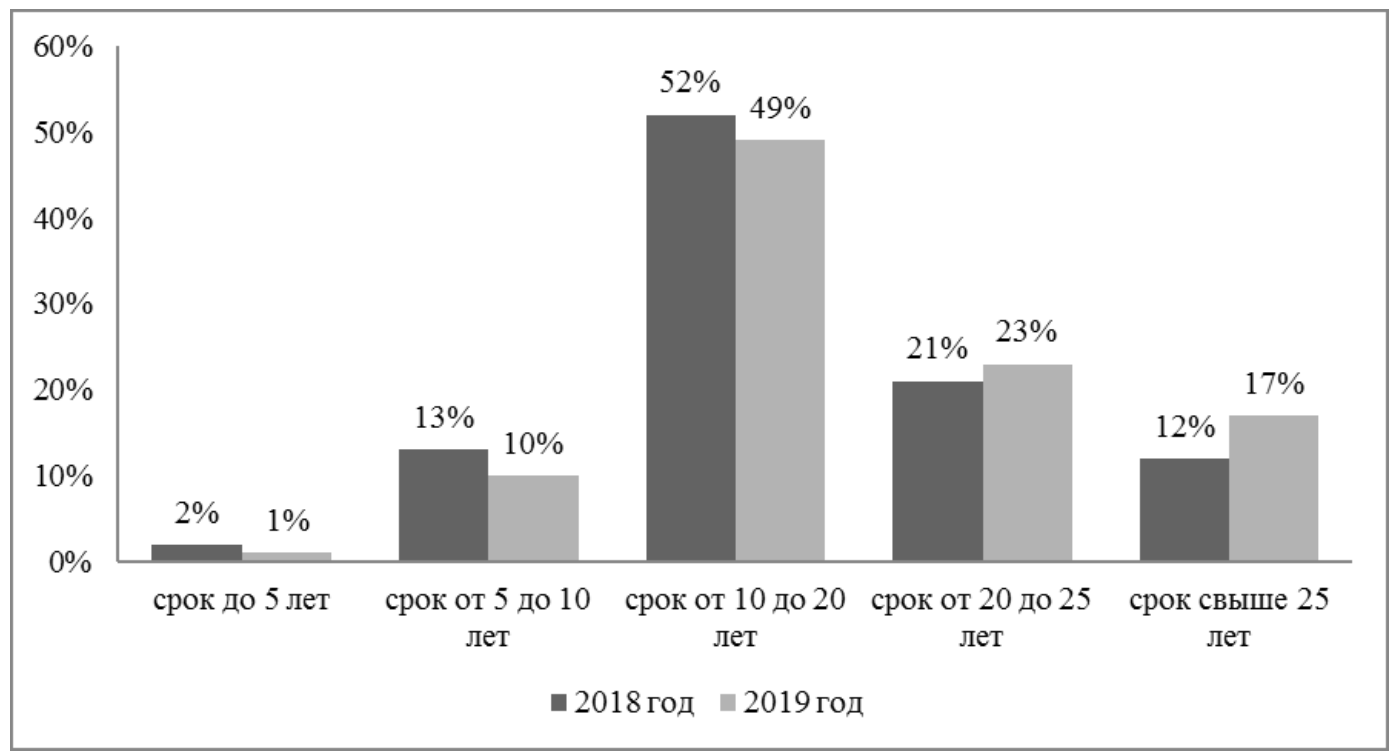

Рис. 3. Структура ипотечного кредитного портфеля банковского сектора по срокам кредитования в 2018-2019 гг. 
чительно увеличился сегмент ипотечных кредитов размером от 5 до 10 млн. рублей - с 11 до $14 \%$.

Поскольку наблюдается увеличение среднего размера ипотечных ссуд, заемщики предпочитают кредитование на более длительный период в целях ограничения роста долговой нагрузки и формирования удобного графика платежей. В 2019 году средний срок по ипотечным ссудам увеличился на 1,5 года и составил 18,2 года. При этом наблюдается резкое увеличение доли ипотечных кредитов сроком более 25 лет - с 12 до 17 \% объема выданных кредитов (рис. 3).

Несмотря на ограничение уровня платежеспособного спроса населения в отношении ипотечных кредитов, тенденция снижения величины первоначального взноса, наблюдавшаяся на протяжении 2018 года, в 2019 году приостановилась. С 01.01.2019 Центральный банк Российской Федерации произвел повторное увеличение коэффициентов риска по ипотеке с первоначальным взносом менее $20 \%$. В результате этого некоторые банки ввели в начале 2019 года надбавку к процентной ставке при условии уплаты первоначального взноса размером менее 20\%. Даже если данная мера не препятствовала выдаче подобных кредитов, их привлекательность для заемщиков снизилась.

По аналитическим данным Дом. РФ. «Итоги развития рынка ипотеки в I квартале и апреле 2020 года» начало 2020 года было благоприятным для ипотечного рынка. В апреле по причине ухудшения макроэкономической ситуации упал спрос на жилье и, как следствие, сократилось ипотечное кредитование: по предварительным оценкам, было выдано около 90 тыс. кредитов на сумму 208 млрд. рублей, что меньше по сравнению с аналогичным периодом 2019 года на 17\% в количественном выражении и на 13\% в денежном выражении [8].

В целом в 2020 году рынок ипотечного кредитования России может оказаться под давлением вследствие снижения темпов экономического роста и инфляционных рисков в результате снижения цен на нефть и введения ограничительных мер.

По данным аналитической записки «Ипотека и доступность жилья», подготовленной департаментом исследований и прогнозирования Банка России в марте 2020 года: «Форсированный рост ипотечного кредитования может снижать макроэкономическую устойчивость. Ускоренный рост этого сегмента кредитования увеличивает риски возникновения кризиса на рынке жилья, а также усиливает его негативные макроэкономические последствия» [9].
Рейтинговое агентство «Эксперт РА» прогнозирует развитие рынка ипотечного кредитования по позитивному, умеренно негативному и кризисному сценарию [3].

В соответствии с позитивным сценарием развития на рынке ипотечного кредитования предполагается, что изменения в денежно-кредитной политике Банка России могут произойти в виде приостановления цикла снижения уровня ключевой ставки, но не приведут к его росту. В соответствии с данным прогнозом объем предоставленных ипотечных кредитов в конце 2020 года может увеличиться на 10-15 \% и составить от 3,1 до 3,2 трлн. рублей, а средневзвешенная ставка будет находиться на уровне около 8,5 \%. Основным фактором, оказывающим влияние на снижение средней ставки, является развитие ипотечного кредитования в рамках госпрограмм, ставки по которым находятся в пределах от 2 до $5 \%$. Однако отрицательное влияние могут оказать возможное введение показателя предельной долговой нагрузки для ипотечных ссуд, который уже применяется в потребительском кредитовании, а также увеличение цен на недвижимость. Хотя при введении предельной долговой нагрузки возможно сохранение высокого качества ипотечного портфеля.

Наиболее вероятным считается умеренно негативный сценарий развития рынка, предполагающий по итогам 2020 года рост инфляции выше таргета в $4 \%$ годовых и, как следствие, рост ключевой ставки регулирующего органа до 7,0-7,5 \%. Реализация данного сценария может быть вероятной, если среднегодовая цена на нефть марки Brent будет составлять 40-45 долларов США за баррель. В этом случае объем выданных ипотечных кредитов будет меньше по сравнению с 2019 годом на 10-12 \% и составит порядка 2,5-2,6 трлн. рублей, что будет связано с ростом ипотечных ставок до $10 \%$ и снижением реальных доходов населения. В 2020 году банки столкнутся с проблемами по управлению качеством ипотечного портфеля, возникающими на фоне снижения платежеспособности населения вследствие общего спада экономики страны. Ожидается также рост объема просроченной задолженности по ипотечному кредитованию за год на 5,0-10\%, но ее доля в структуре ипотечного портфеля не должна превысить 1,5 \%. При этом в последующие 2-3 года возможен более ощутимый ее рост по причине возможного роста просроченной задолженности заемщиков, которые получили кредит в период ипотечного бума. Однако поддержку качеству ипотечного портфеля может оказать закрепленная в законодательстве с 2019 года возможность предоставления ипотечных каникул для заемщиков, которые оказались в трудной жизненной или финансовой ситуации, что в долгосрочной перспективе поможет увеличить доверие к ипотечным кредитам в целом. 
В соответствии с кризисным сценарием развития предполагается, что вследствие существенного углубления негативных явлений в экономике, снижения среднегодовой цены на нефть до 35 долларов за баррель, отказа от валютных интервенций Банка России и значительного обесценения рубля, а также роста инфляции до 7-8 \% по итогам года произойдет рост ключевой ставки до 9-10\%, а ипотечные ставки будут составлять около к $12 \%$. Банками ужесточатся требования по отношению к новым заемщикам, например, со стороны роста требований к первоначальному взносу, а спрос на ипотеку значительно упадет. В случае реализации кризисного сценария объем выданных ипотечных кредитов может сократиться на 20-25 \% и составить от 2,1 до 2,2 трлн. рублей. В соответствии с данным сценарием также предполагается снижение реальных доходов населения, что негативно скажется на платежеспособности заемщиков и, соответственно, может способствовать увеличению просроченной задолженности в ипотечном портфеле более чем на 10 \% по итогам 2020 года.

По прогнозам финансового института развития в жилищной сфере ДОМ. РФ [8], населением будет реализовываться отложенный спрос, и за 2020 год будет выдано порядка 1 млн. кредитов на общую сумму около 2,5 трлн. рублей.

На фоне продолжающегося стремительного роста ипотечного кредитования в период с 2017 по 2018 гг. некоторые экономисты опасались угрозы образования в стране ипотечного пузыря, аналогично ипотечному кризису США 2007-2008 гг. Ипотечный пузырь представляет собой ситуацию на ипотечном рынке, когда высокие темпы роста ипотечного кредитования в определенный момент времени приводят к наращиванию просроченной задолженности, росту доли неплатежеспособных заемщиков, обесценению ипотечных ценных бумаг и банковских залогов, падению цен на недвижимость и, как следствие, обвалу ипотечного рынка и всего рынка недвижимости.

Глава департамента денежно-кредитной политики Банка России Кирилл Тремасов также обращал внимание на то, что ускорение роста рынка ипотеки в стране происходит из-за снижения реальных доходов населения и негативной динамики цен на жилье. «Вряд ли это можно назвать здоровой тенденцией. Да и сами темпы роста в слабо растущей экономике выглядят очень нездоровыми. Подобные темпы (30-40\%) наблюдались у нас на пике бума в сегменте потребительского кредитования в 2012-2013 гг. Это был классический пузырь, схлопывание которого похоронило несколько банков и принесло огромные проблемы всем остальным», указывал он [5].

Последние несколько лет ипотечный рынок в Рос- сии считается драйвером развития в розничном кредитовании, однако, по мнению ряда экономистов, повода для беспокойства не имеется, так как доля ипотечного кредитования в формировании ВВП России составляет около 5\%, поэтому риск развития «пузыря» они считают невеликим [4].

Чтобы ограничить риски ипотечного кредитования, Банк России с 1 января 2018 года принял решение об ужесточении требований по отношению к резервам ипотечных кредитов с невысоким первоначальным взносом. В результате рядом банков было принято решение об увеличении минимального значения первоначального взноса до $20 \%$.

По мнению информационного агентства «РИА Новости», российский рынок ипотеки пока не испытывает существенных проблем [5]. По данным Объединенного кредитного бюро (ОКБ), [7] по результатам первых двух месяцев 2020 года объем ипотечных кредитов увеличился на $21 \%$ по сравнению с аналогичным периодом 2019 года и составил 435 млрд. рублей. Средний размер ипотечного кредита увеличился до 2,44 млн. рублей, а средний срок кредитования до 16,5 года. По мнению экспертов, это произошло на фоне установления рекордно низкого уровня ставок по ипотечным кредитам, а также стремления населения инвестировать в недвижимость В период кризиса.

«Чтобы не тормозить сделки по приобретению жилья в ипотеку, которые требуют личного участия заемщика, мы временно смягчаем для банков требования по идентификации клиента - и банки смогут проводить ипотечные сделки удаленно», - объявила глава Банка России Эльвира Набиуллина, отметив при этом, что, несмотря на пандемию коронавируса, «спрос на ипотечные кредиты в России сохраняется и будет расти в среднесрочной перспективе» [5].

В целях дополнительной поддержки рынка ипотечного кредитования Банком России приняты следующие меры:

- уменьшение надбавок к коэффициентам риска по ипотечным кредитам, которые были выданы до 01.04.2020, что позволит высвободить около 110 млрд. рублей;

- смягчение регулирования в области ипотечных облигаций, что способствует увеличению ликвидности рынка ипотечных облигаций и привлечению в сектор дополнительных средств. Благодаря этому происходит формирование надежного источника долгосрочного фондирования ипотечного кредитования, который снижает процентный риск в банковском секторе, что особенно необходимо в условиях высокой волатильности. 


\section{ЛИТЕРАТУРА}

1. Положение Банка России от 28.06.2017 № 590-П (ред. 0т 16.10.2019) «0 порядке формирования кредитными организациями резервов на в0зможные потери по ссудам, ссудной и приравненной к ней задолженности» [Электронный ресурс]. - Режим доступа: https://cbr.ru/faq_ufr/dbrnfaq/ doc/?number $=590-\Pi$

2. Центральный Банк Российской Федерации. - Режим доступа: http://www.cbr.ru

3. Рейтинговое агентство «Эксперт РА» [Электронный ресурс]. - Режим доступа: https://raexpert.ru/

4. Финансовый супермаркет «Банки. ру» [Электронный ресурс]. - Режим доступа: https://www.banki.ru/

5. Информационное агентство «РИА Новости» [Электронный ресурс]. - Режим доступа: https://ria.ru/

6. Федеральная служба государственной статистики. - Режим доступа: http://www.gks.ru/

7. Объединенное кредитное бюро. - Режим доступа: https://bki-okb.ru/

8. Финансовый институт развития в жилищной сфере - «ДОМ. РФ». - Режим доступа: https://дом.рф/

9. Аналитическая записка «Ипотека и доступность жилья» [Электронный ресурс]. - Режим доступа: https://www.cbr.ru/Content/Document/File/105729/ analytic_note_20200312_dip.pdf

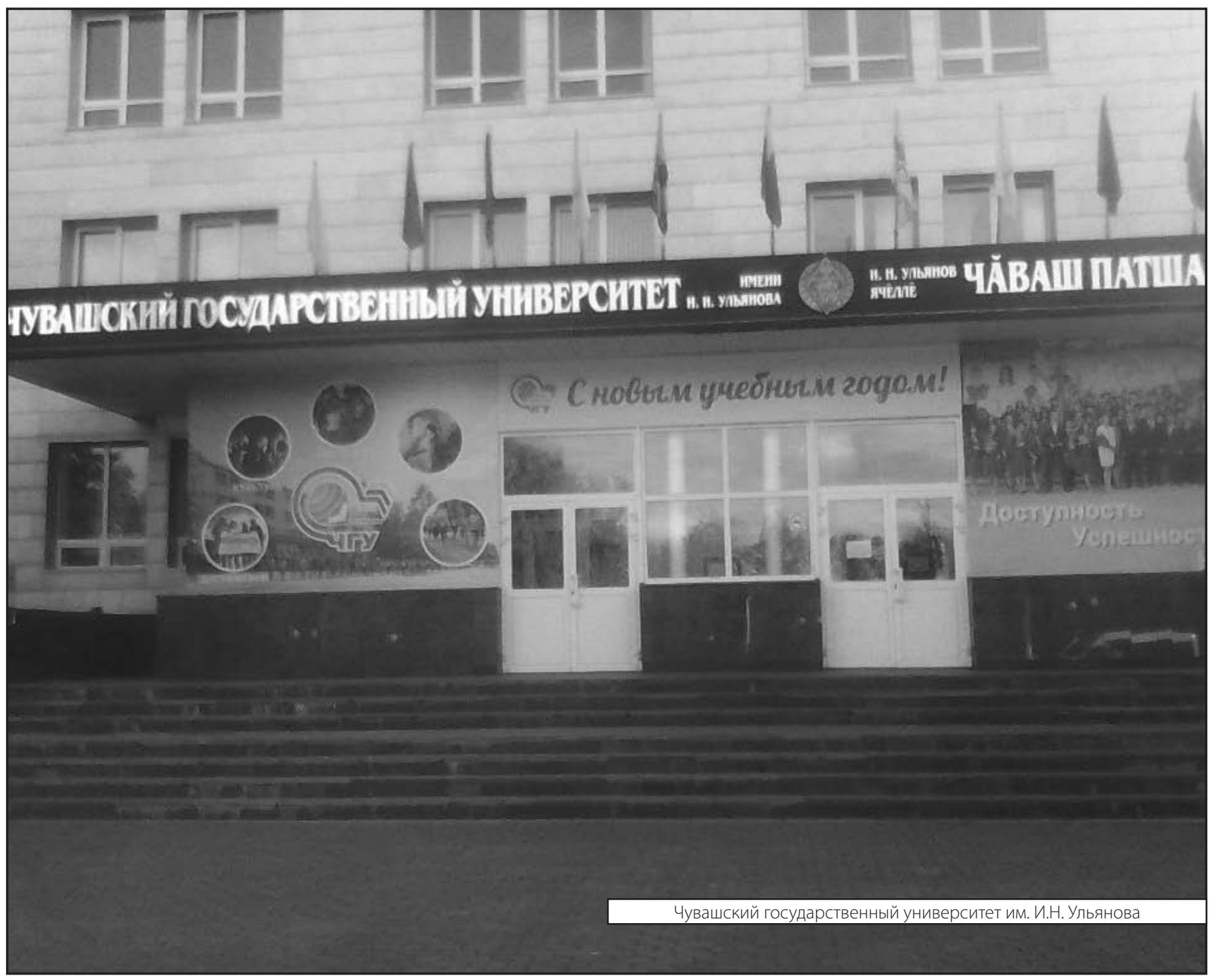

